\title{
ÍNDICE
}

Presentación

Patricia Fernández Martín, Alexandra Duttenhofer, Daniel M. Sáez Rivera, Francisco Javier Herrero Ruiz de Loizaga

Bibliografía de José Luis Girón Alconchel......

\section{Angela Bartens}

Cómo se crea una lengua: reflexiones acerca del cántabro, el mirandés, el valenciano y los criollos de Alta Guinea.

Rafael Cano Aguilar

Los nombres de la lengua en la España de los Austrias

Juan Antonio Chavarría Vargas

Nuevas aportaciones al léxico romandalusí desde el corpus de los LR (Libros de Repartimiento) y LAR (Libros de Apeo y Repartimiento) del Reino de Granada (ss. XV-XVI) [2. ${ }^{a}$ parte]....

\section{Alexandra Duttenhofer}

Algunos apuntes sobre la función textual de la construcción anafórica el dicho + sintagma nominal en La conquista del Perú, de Alonso Borregán.

Patricia Fernández Martín

Las perífrasis verbales no factuales en la Carta a sor Filotea de la Cruz: clasificación y estudio

\section{Anton Granvik}

Variantes (in)visibles y sedimentación en la construcción $\mathrm{N}$ de que en Lope de Vega, Tirso de Molina y Calderón de la Barca. 
Francisco Javier Herrero Ruiz de Loizaga

Estudio histórico de los operadores de duda alquieras, quizá(s), quién sabe

\section{Luis Martínez-Falero}

Tipología y genealogía del uso del discurso directo en la literatura medieval castellana (perspectiva teórica y comparada).

Antonio Narbona Jiménez

;Anda que ha tardado (bastante) en dejarla! ;Anda que no se lo he dicho (yo) (muchas) veces!

Álvaro S. Octavio de Toledo y Huerta

De la localización a la concesividad (y más allá): auge y caída de la locución conjuntiva en medio de durante el primer español moderno (ca. 16751825)

Daniel M. Sáez Rivera

La historia de alias en español entre gramaticalización o contacto lingüístico y lexicalización

Cristina Sánchez López

Gramaticalización y variación gramatical: el caso de las oraciones concesivas introducidas por así.....

\section{Ana Stulic}

Dos senderos de gramaticalización que se bifurcan: el nexo subordinante loke y el pronombre interrogativo loké ( < lo que) en judeoespañol

Los autores 